\title{
Collective Responsibility: Organizations as Organic Entities
}

\author{
Robert Albin \\ Department of Liberal Arts, Sapir College, Shaar-Henegev, Israel \\ Email: albin@sapir.ac.il
}

How to cite this paper: Albin, R. (2016). Collective Responsibility: Organizations as Organic Entities. Open Journal of Philosophy, 6, 392-405.

http://dx.doi.org/10.4236/ojpp.2016.64036

Received: September 10, 2016

Accepted: October 30, 2016

Published: November 2, 2016

Copyright $\odot 2016$ by author and Scientific Research Publishing Inc.

This work is licensed under the Creative Commons Attribution International

License (CC BY 4.0).

http://creativecommons.org/licenses/by/4.0/

\begin{abstract}
The question of who exactly is responsible for an organization's actions cannot be too carefully considered, as a clear understanding of this point is crucial from ethical, moral, managerial, and public perspectives. This article discusses how to justify a non-participant member's responsibility for the actions of other group members, establishing collective responsibility. The article develops a novel context-depended framework that solves this problem by supplying good grounds for perceiving organizations as organic entities, which is adequate for establishing collective responsibility. I suggest that to be responsible for the actions of an organization, one has to belong to that organization, even if one has not taken any part at any level in group actions. The more regular concept of causal responsibility is not applicable here since it cannot account for the responsibility of non-participant members.
\end{abstract}

\section{Keywords}

Collective Responsibility, Collective Agency, Organic, Team, Organizations

\section{Introduction}

Those arguing that collectives bear responsibility for their actions face the problem of how exactly this collective responsibility falls onto each individual group member. It is especially difficult to determine to what extent, if any, an individual bears responsibility for collective actions that she or he has not taken part in at any level or is not even aware have taken place. The question of who exactly is responsible for an organization's actions cannot be too carefully considered, as a clear understanding of this point is crucial from ethical, moral, managerial, and public perspectives. One minor note is to be made right at the beginning: while "collective action" is a general term that can be ascribed to several types of collectives: groups, mobs, teams, parties, nations, and others, this discussion will be limited to one type of collective alone organizations. Organiza- 
tions seem to attract intense public attention in terms of responsibility for their deeds. More specifically, formally structured organizations will be the focus of this discussion. Though nations (not states), cultures, mobs, and other accidental gatherings (tube or airplane passengers, for instance) are cases of collectives, their boundaries are less well-determined. The question of how to determine who is part of such collectives raises serious difficulties as only in rare cases, if any, does one act on behalf of all other accidental participants. Hence, business organizations and NGO's, along with most governmental organizations and many civilian ones fall into the domain of this discussion.

The philosophical difficulty here is whether and how to justify a non-participant member's responsibility for a collective action, thereby establishing collective responsibility. In seeking to answer this question, I suggest that we consider organizations not as mere aggregations of individuals, but as organic entities, which is adequate for establishing collective responsibility. In what follows I provide the grounds for such a perception of organizations by adopting Bertrand Russell's (1905) suggestion that building arguments is not the only successful way of dealing with philosophical difficulties. Following Russell's suggestion, I do not set out an argument but instead propose some edifying remarks, which originate in day-to-day organizational life, in favor of a picture of collectives as organic entities. This change in our perception of organizations will allow us to find a more elegant solution to the quandary of collective responsibility, sidestepping the philosophical difficulty rather than solving it. Considering organizations as organic entities allows us to avoid understanding their responsibilities in terms of inner-organizational causalities and the connections between sub-organizational components. Instead, the responsibility of a non-participant member can be determined by being a part of the organization.

Nevertheless, this does not imply in any sense that organizations are, in their very essence, organic entities; rather, my suggestion should be taken as a phenomenological reminder, i.e. as one that singles out the way they appear to us, rather than an ontological conception that indicates the absolute nature of organizations. As the discussion develops, I suggest considering this way of viewing organizations as non-metaphysical. Here, "organic" is only a metaphor, although a powerful one, since it provides a better justification and explanation for the collective responsibility of organizations.

\section{The Reductionist Approach}

All sorts of solutions have been adopted by philosophers in their quest to explain and justify a non-participant's responsibility for a collective action. For some the difficulty steams from the existence of two separate levels of responsibility: collective responsibility and individual responsibility. Whereas both individuals and organizations are thought to be moral agents, they qualify in different ways. Organizations exist and operate by virtue of their members. The members bear responsibility as individuals and as the whole organization at the same time. Some scholars have noted that the collective level of responsibility can be considered dependent upon the individual level, which 
sustains it since the organization ceases to exist in the absence of its members (Pettit, 2007; Mäkelä, 2007; Coop, 2007). Some have worked out a solution from the bottom up. As the individual level has a logical primacy over the collective level, they see collective responsibility as constituted by individual responsibility. The problem was how to connect each and every member's actions to the actions of the organization. This line of thought, which relates to collective responsibility in terms of individual responsibility and actions, takes a reductionist approach. Coop (2007) is an exception, however. According to his view, an organization can bear responsibility even when no one of its members shares it. This of course does not qualify as a reductionist approach and as such it is beyond the reach of this article.

The issue of who is a non-participant member should be further clarified. I suggest considering all acting members of an organization as bearing responsibility for its actions, though some of these members may not participate or even know of those actions. Some may spend time on vacation, or stay at home sick, while the above actions are taking place. Nevertheless, as acting members of the organization they bear responsibility for its actions. After all, the notion of collective responsibility implies that an entire group bears responsibility for all of its individual member's actions, even if one or more of these members was not in any practical sense part of such actions.

Peter French $(1979,1984)$ presents corporations as bearers of moral responsibility by means of its (managers) members' actions and decisions. Although he aims at a picture of corporations as moral persons, he depicts corporations in formalistic and, as a consequence, mechanistic terms. He develops the idea of a Corporation Internal Decision Structure (CID) as a "device” by which a corporation reveals its intentional nature. This formalistic view leaves little room-if any-for non-participant individual responsibility for collective actions. Amy Sepinwall's (2010) work aligns with the reductionist approach. In what follows, I discuss Sepinwall's formulation of and solution to the problem. I then explain why the distinction between collective and individual perspectives of responsibility cannot be bridged as easily as Sepinwall suggests, and I will show that her account of collective responsibility is not feasible.

Sepinwall asserts that every individual member of an organization is responsible for any actions taken by the organization, even if a member had no part in a given action. In support of this, she proposes two explanations that establish a connection between a non-participating member and the group's act, placing responsibility on this individual member for other group members' actions. According to the first explanation, a group member contributes to the identity of the organization (its "calling card") and according to the second the group member contributes to the creation of its rules (laws of recognition), namely the demand to act according to any informal organizational norms. From this perspective, there are two levels of acting in the name of an organization: being directly involved in an action, such as a lifeguard at the beach who rescues a drowning child from stormy waters; and being involved indirectly, such as in the previous example, being a lifeguard instructor who decides how water rescues should be conducted, thereby helping in the shaping of organizational rules (laws of recognition). 
Sepinwall's explanation relates to indirect contributions to a collective action. However, Sepinwall argues that both of the criteria give rise to individual responsibility for the collective's actions:

Shared responsibility requires a connection, but that connection can arise even if there is no direct pathway tying the member from some rule of recognition in which she participated to the act of the group. Instead, the connection arises just so long as the member may contribute to some of the group's rules of recognition, or just so long as she may contribute to the group's calling card. $(2010,227)$

Here we face a problem with a dual nature. Sepinwall acknowledges that it is extremely hard (if not impossible) to disentangle and to trace the influence of each individual member's actions on the group's actions. She therefore assumes that each member has to be connected to the acts of the group, either by "contributing to the group's rule of recognition" or "to the group's calling card." However, this assumption needs to be better supported. Situations in which a group member's actions are in no way related to those of the group are common; for example, it would be almost impossible to make a connection between the actions of a hotel porter and a decision by the upper management to build a new hotel. I am not suggesting that no such connection exists, but rather that there are cases in which such a connection exists and others in which no such connection exists. The assumption that every group action is influenced by every individual group member's actions is a contingent one, and not a necessary truth; it should therefore be scrutinized separately for each and every case. This is true not only with regard to causal influence on group actions, but regarding individual contributions to group identity, as well.

The second difficulty with Sepinwall's assertion further weakens her perspective. It is reasonable to think that not every act on the part of individual members has a causal influence on the group's actions; if so, then Sepinwall must put forth some criteria for distinguishing between individual acts that do or do not influence the group's actions. However, she offers no such criterion for distinguishing between the two. The hotel porter in the previous example may prefer a hamburger to a steak; he may speak English fluently or poorly. Such features remain within the bounds of personal idiosyncrasy, and cannot be included as influencing the group's actions.

Examples such as this suggest that assigning individual responsibility for all group actions cannot be appropriate. Taking this a few steps further, the distinction between the collective and the individual perspective on responsibility collapses. Pekka Mäkelä (2007) suggests that collectives cannot qualify as free moral agents. Accepting Pettit's (2007) thinking, Mäkelä argues that collectives can be held to be moral agents only if they are intentional agents in the same way that individuals are. Furthermore, he holds that the source of the group's collective intentions, upon which the group acts, is generated by individuals, who are distinct from the group. From this perspective, the group is the vessel through which individual agents can fulfill their individual intentions. Mäkelä maintains that even when individual members seem to be acting on behalf of 
the organization, they do so according to their own personal understanding and will. Through these personal intentions, the collective's aims and ends are determined:

The important point is that individual members are in control over their part actions as intentional agents distinct from the collective agent $[\ldots]$ The individual members are always to decide whether to act in ways that constitute the collective agent's acting in a certain way the individual members are in a "check-point position" with respect to the collective agent's action [...] Thus, collective agents necessarily lack the control necessary for being able to choose between options on the basis of judgments about their value (Mäkelä, 2007: p. 465).

Here we find a distinction between two levels of responsibility, with only the upper level having authority over collective acts, since individualistic intentions are the source of collective ones. Mäkelä would identify individual members as being the authorities at this level of responsibility, while Pettit would suggest that both the individuals' intentions and collective intentions have equal authority simultaneously. Along with the question of authority, both Pettit (2007) and Sepinwall (2010) are concerned about the connection between individual and collective responsibility. Pettit argues that responsibility on the group level is made up of individual members' agency; the individual members act on behalf of the organization, constituting, in part, its collective responsibility. While these ideas are appealing, they overlook Sepinwall's most persistent question: by what means, exactly, can a non-participant individual be held responsible for another organization-member's actions?

To briefly summarize, both Sepinwall and Pettit consider collectives responsible for their actions, and both see the individual agent as a means for establishing collective responsibility. In trying to connect the individual member's actions to group-level actions, both Sepinwall and Pettit regard collective actions as a tangle of many individual actions, which work together in a joint effort towards attaining some targets or goals. Hence, collective responsibility is constituted by the fact that each individual's efforts are connected, directly, through causality or by acting in the name of the organization, or non-directly by means of contributing to the organization's calling card.

Another form of the reductionist approach is to consider reasons rather than causes to be the hallmark of collective responsibility. In this context, Tracy Isaacs (2006) uses "collective intentions" as a means of establishing collective responsibility. Isaacs borrows and develops Bratman's (1993) somewhat raw idea of collective intention. In short, she suggests that the criterion for collective responsibility can be found in the collective intention of a group to act in such and such a way. Isaacs is well aware that every intention is one's individual intention and that the aggregation of all members' intentions is not to be confused with the intention of the collective:

According to my view, collective intentions are real: they are states of affairs. They are not collections of individual intentions that arise out of group structures or that group structure causes [...]. It is highly relevant that these intentions are interrelated, forming a powerful web that results in collective action. $(2006,70)$ 
An essential part of Isaacs' account of collective intention is the relations between the individual intentions of each and every member of the group. This web of intentions is the collective intention that grounds the responsibility of a group. I see two major problems with this view. First, Isaacs' account neglects an important case of collective action in which a group member (or members) has no real knowledge of the group's objectives. In this case this member cannot be found to bear responsibility for the collective action because she does not share common intentions with the group. Second, for an intention to be recognized, it should be distinguished from any other. I believe that Quine's statement that there is "no entity without identity" is of relevance here. This phrase states that this entangled and interwoven web of the intentions of all members of a group cannot be considered an intention on its own because it lacks a clear description that is distinct from those of the members.

\section{Organizations as Organic Entities}

In understanding the question of how to justify non-participant member's responsibility for the group actions, some additional points and questions need to be addressed. To this end, I propose adopting another way of thinking about collectives: as entities that differ from mechanisms made up of individuals. This new perspective circumvents the problems encountered by previous formulations.

Groups play a unique role in human existence, enabling phenomena such as language, religion, ethics, art, and many more. Within the context of groups, human creations are initiated, designed, and exercised as common creations. For this reason, I suggest considering groups, especially organizations, as organic modes of human existence. However, viewing organizations from this angle does not imply an ontological burden; it is only meant to serve as a metaphor for deepening our understanding of human life. This line of thought opposes the view of collectives as mere mechanistic artifacts that are put to work in the service of a given party's interests.

Considering organizations as organic modes of human existence implies that the difference between the individual level and the collective one is not a matter of quantity but a matter of categorical divide. G.E. Moore (1903) once wrote that "the value of a whole must not be assumed to be the same as the sum of the values of its parts". I maintain that this view also applies to organizations, whose individual members are not merely mindless component parts. In line with Robert Mayhew's (1997) interpretation of Aristotle, I suggest that the relationship between individual members and the group is more akin to the relationship between a hand and an entire body, rather than that between a spare tire and a car. In this metaphor, a tire is still a tire even if it is not connected to a car; it fully retains its identity when separated from the larger whole, and, more importantly, it can be successfully used on almost any car. In contrast, one cannot remove and replace family members following a universal pattern: if a mother dies and her husband remarries, the new woman will never fully replace the lost mother, even if she legally adopts the children and acts as a mother to them. One cannot replace a mother as one replaces a tire in a car. 
One might respond to this argument by claiming that organizations and families are very different. Organizations are created using a formally determined structure; in conjunction with other components, this structure defines the group's identity, which is something beyond the identity of its constituent members. Unlike families, organizational structure is mechanical; it is defined by hierarchical and formal relationships between functional components, as opposed to between individuals.

To this we could first reply that Western medicine encourages a mechanistic attitude towards human beings, one salient expression being procedures such as organ transplantation. However, this attitude is no more than a choice embraced by Western cultures, which could have adopted different choices. For example, some Asian cultures hold more holistic, less dualistic attitudes, as evidenced by medical techniques such as acupuncture and reflexology. The current widespread conceptualization of organizations as mechanistic reflects a choice: we could change our perspective if such a change would be useful and would satisfy our needs. Medicine is not the only example of a thing with more than one aspect; many things in our lives are capable of presenting multiple aspects. It is our choice which aspect to use in each and every case. In some sense, a variety of aspects are always there, suggesting themselves to us. I think that this is the case when we consider organizations from a new, organic, perspective. However, there is a further source of support for the organic perspective on organizations in Mark Glouberman's recent book The Raven, the Dove and the Owl of Minerva: The Creation of the -Humankind in Athens and in Jerusalem (2012). Glouberman distinguishes between individuals and particulars as he argues that human beings are particulars (persons) rather than individuals (Glouberman, 2012):

[T] hough we have a physical basis, we are not (pieces of) nature; we are irreducible to nature. God is like us [...] each one of us is like God, and vice versa [...] the one-ness of the biblical God is the one-ness of a person, neither more or less robust. $(2012,304)$

Individuals, according to Glouberman, are like atoms of the same element, meaning that any individual can take the place of any other individual. This is not the case with particulars, as manifested by our love for specific people and our fear of their death. By loving other human beings and by fearing their death we come to recognize their particularity for us.

Understanding people in this way reveals some of the tensions between the constructs of individuals and particulars in an organization. Although organizations operate through their individual members, these members are not mere individuals, but also particular persons. While their individuality is somewhat masked by their group identification and assignments and by the management's desire to present a unified front, their personal characteristics shine out from monolithic organizationally and determined behaviors. Although many sports teams exist, for example, each one of them has its own idiosyncrasies. Corporations are characterized in this way as well, and even to a greater extent. While the management tends to work towards shaping particular em- 
ployees into individuals, the employees strive in the opposite direction, wishing to be regarded as particular employees and humans. Nevertheless, all organizations recruit and fire employees, manifesting a quest for particularities alongside individuals, which in turn determine the organization's identity. Particular employees do not act as if they are bound by organizational charts. They may feel proud of belonging to a team, and may come to feel beholden to other team members. Such feelings of obligation can spread outside the context of the team's sphere of influence, being expressed in significant friendships or even marriage. Despite the organizational charts that dictate relationships on paper, the connections between individual members in organizations are not only rational and functional, but often also emotional.

Many senior corporate executives acknowledge the tremendous influence of this emotional factor on employees. For this reason, organizational codes of ethics often demand a devotion to the corporation akin to that of soldiers to armies; employees are instructed to not divulge corporate secrets, to always be well-groomed, and to have good general conduct. Being part of a group can generate feelings of self-respect, self-esteem, and vocation, even though these are not among the necessary or even official goals of the group. In becoming group members, individual persons can receive more than the mere amplification of their capacity to reach their goals. This allows the organization as a whole to transcend the sum of its component parts.

Linda Radzic's (2001) argument comes close to an organic one. She establishes a non-participant's responsibility for the deeds of a collective on being a part of a collective on being one of its members. Although her work focuses on collective crimes, rather than the day-to-day lives of civil collectives or business organizations, I find it highly relevant to my line of thought. In brief, she argues that non-participating members should be held responsible for their group's crimes by virtue of belonging to that group. According to Radzic, non-participating members of any group who benefit from, for example, discrimination by other group members against persons who are not part of the group are to be held responsible for those actions. Their collective identity makes them responsible, as they are part of the oppressors' group.

However, Radzic fails to distinguish between two kinds of beneficiaries: those who are part of the oppressors' group, and those who are not, but who still benefit from the discriminatory actions. The presence of this second group suggests that what makes non-participants responsible for collective actions is not their collective identity, but rather the fact that they benefit from these actions, regardless of their group membership status. Following Radzic and Margaret Gilbert's (2006) work on the subject, I tend to think that one's belonging to a collective is a significant factor in determining whether one should be held responsible for the actions of a group. Later in this article I develop this argument concerning how belonging to an organization makes its nonparticipant members responsible for the group's actions.

History has shown that being part of a group can have an intoxicating effect. Feelings of solidarity mingle with devotion, resulting in a willingness to sacrifice one's time, money, and sometimes even one's life to serve the general good. Benedict Anderson's 
(1991) Imagined Communities draws the reader's attention to the experience of those who share a common sense of community: in the form of the nation. Nations have the power to produce a number of artifacts, including art, poetry, language, jokes, fables, games, and foods. None of these things can be entirely created by any one of its individual members; such creations require a larger human bedrock, a surrounding in which these practices can be developed and nourished. This fact encourages us to regard groups such as corporations, political parties, churches, and so on as organic entities. Again, I want to emphasize that these statements on the organic nature of these organizations are not metaphysical, but phenomenological.

A similar premise can be found in Rousseau's "general will". Distinguished from any personal will, this general will is not the sum of all personal wills in a society, but rather a unified will seeking the common good of the community, which arises given the existence of a community. The general will allows the community to act according to a single will, which can be understood as that of an organic entity. This organic entity has a non-linear structure, comprising parts connected through horizontal and other complex pathways. Seen as an organic entity, every part affects and is affected by the entire whole; all of the organization's acts are interwoven in complex ways. Pettit develops a similar account of a collective intentional agent; however, he pairs this with the mechanistic notion that the collective acts in a framework of individual acts, in which its responsibility is grounded:

[T] he group agent will be fit to be held responsible for ensuring, or more or less ensuring, that one or more of its members will perform in the relevant manner. The contributing member or members of the group will not be absolved thereby, however, of their own responsibility. For, other things being equal, they will each be fit to be held responsible for the fact that it is they who actually help to get the action performed. $(2007,192)$

Pettit's response may be read as a moderated reductionistic and mechanistic version of collective responsibility as he still relates to organization's actions in individualistic terms. A further deepening in this direction may evoke another response to my organic line of thought. One can argue that the change of perspectives that I have suggested toward organizations is of a metaphysical nature, since it is a generalization, as much as the mechanistic conceptualization that I have just opposed. Evidently there are cases in which it is hard to define who exactly is the responsible agent-the organization or the individual who acts in its name. Consider the previous example of the hotel porter. This man, along with all the other hotel staff, may be deemed responsible for the death of a guest with a severe peanut allergy, who was served a dish containing peanut butter from the hotel kitchen, despite having informed the kitchen and wait staff of his allergy in advance. Under such circumstances, it would not be odd for the guest's family to see the hotel, as a whole, as being responsible for the tragic death of their loved one. Holding the hotel responsible for the tragedy is justified by the fact that all of its workers were acting in its name. This is how organizations work. They act through their mem- 
bers. Following this line of reasoning, the family would be justified in holding the hotel as a whole as responsible for the death of their loved one and hence, expecting compensation from the hotel as a whole business organization, not from each and every one of its workers separately.

In case the porter had known in advance, by chance, that the hotel kitchen staff were capable of such misconduct, could he have mitigated his own level of responsibility or even removed it all together? Well, he could, of course, have informed, anonymously or otherwise, the hotel management about the danger. He could also resign from the hotel. All of these steps could help to reduce his responsibility. In other cases employees who know that their employers' actions endanger other people may "blow the whistle" by telling the press about those dangers. According to the view I have suggested here, the most effective step an employee can take in such a case is to resign or leave the organization, while informing inner or even outer officials of the facts. Rupturing oneself from an organization in advance ensures one's innocence. Nevertheless, such measures are seldom taken since the strains of providing for oneself and others, as well as other personal interests, impinge on such practices.

However, from inside the hotel, the exact person or persons who bear responsibility for the guest's death can and will be determined with great accuracy. The management might find that the cook who was on duty on the night of the accident is to be blamed, since she was the one who used peanut butter in the dish, despite having received notice of the guest's deadly allergy. This is an inside perspective, one that is only valued from within. This fine distinction in responsibility is not of any value to the guest's family or to the broader public of consumers in general. All that consumers are interested in is the outer perspective, which determines the collective responsibility of the hotel as a whole. According to the outer perspective of responsibility, the porter shares responsibility for the guest's death; in contrast, from the inner perspective, the same porter is not responsible for the tragedy at all, since he was not the one who prepared the lethal dish. According to this account, the establishment of responsibility for a specific agent should be context dependent either on an outer or an inner point of view.

The above discussion does not eliminate all complexity regarding who is responsible for the accident. Consider the case in which the porter to which we refer is a new recruit to the hotel, who was only hired the day before the accident and has yet to work a single shift. Would he, under such circumstances, be regarded as responsible for the death of the guest with the allergy? Given such mitigating information, we probably would not consider him responsible, arguing that, although he had been formally recruited, he was not yet a full member of the hotel organization. This is the sort of borderline situation that demonstrates the ethical importance of belonging to specific groups, while highlighting potentially ambiguous boundaries. This example emphasizes that belonging to a group such as an organization is not a mere formality, but rather a decision that takes into account a number of connections relating to feelings, self-image, and ethical commitments, as well as to the shaping and calibration of one's reactions to other members of the group. 
Another consideration refers to the fact that there are several types of membership, not only one. Being a member of the Protestant Christian Church, for example, is different from membership of a professional union. As this discussion is concentrated on formal structured organizations its modes of membership are relevant here. In particular I find three modes of organizational membership appropriate: acting members, observers, and retired members. Broadly speaking, all of these bear collective responsibility. One might challenge the latter suggestion, as Sepinwall implies, by pointing at the descending degree of involvement of each of the three mentioned groups in organizational actions. Accordingly, acting members are the most responsible while the retired are less so. However, this picture of allocated collective responsibilities emerges from a combination of the intensity of involvement with the actual membership, and according to my opinion does not let any of these members off the hook of collective responsibility.

But what warrants the view that one is responsible for actions that one has not taken? Do retired members still bear responsibility for actions taken while they are retired? I suspect that taking these questions as a sort of challenge to my view of organic collective responsibility steams out from overlooking a subtle aspect of responsibility. Among other things, responsibility is about responding to someone's attitude or actions toward oneself or others with an evaluative attitude (Strawson, 1993; Macnamara, 2011; Watson, 2009). This is how responsibility is practiced and embedded in everyday life. It is likely that knowing someone we have just met is a member of Malaysian Airlines will affect our professional appraisal of him or her, because of the poor degree of flying safety Malaysian Airlines has been associated with in recent years. Strawson indicates that no philosophical justification or its lack can affect our attitudes toward the responsibility of others. In this regard we are what we are. We do ascribe collective responsibility to organizations and individuals, even if in a gradual manner. Among other things, his view entails a prospect of a philosophy that is set on describing the human world rather than justifying it.

Such reflections remind us of the difficulties encountered in metaphysical discussions that aim to establish crossover generalizations, which are best avoided. However, transforming conceptualizations of mechanistic-individual responsibility into collective ones can sometimes involve only minor changes, despite the fact that such changes alter the comprehensive picture as to the responsibility of a group for its actions.

So far, I have criticized the inclination of some thinkers to depict organizations in mechanistic and reductionist terms. Casting organizations as collectively bearing responsibility by virtue of their organic-entity status is helpful in the following sense: it allows us to mitigate the difficulty in answering the question of how a non-participant individual can be responsible for another organization member's actions. The previous analogy comparing the relationship of an individual to her or his hand to that of a corporation to an individual employee can be expanded. For example, say a slave in ancient Rome is whipped for the theft of his master's money. As the lash bites into the 
flesh of his back, would we say that this is unjust, since the back is paying for the crime of the hands? Most would disagree with this line of thought, and, based on our general attitude towards human beings as unified entities with one overarching identity, would say that the punishment was just, in this very narrow aspect. By the same token, we would say to Sepinwall that all team members or corporate employees are mutually responsible for any deed committed by a single member, holding them responsible for their actions as a collective. By holding them accountable in this way, we make each and every one of the individual members accountable for the whole organization, just in virtue of being a part of it. Just as no further biological or ethical connections have to be established in order to prove, in the previous example, that the slave is responsible, not his hands, no other ties have to be established in order to make ethical connections between individual members of organizations.

This argument is by no means a mere analytic maneuver. It is consistent with some traditional ways of conceiving of collective responsibility. The Bedouins, for instance, maintain traditions of blood disputes, whereby retaliation against an innocent individual is an acceptable reaction to a relative's crime (Ginat, 1987). Such concepts of collective guilt later gave birth to collective responsibility (Fletcher, 2002).

\section{Conclusion}

As shown, reductionist approaches toward collective responsibility raise some serious difficulties for its constitution. To overcome these difficulties, I have suggested a context-depended approach, according to which collective responsibility is perceived mostly from an outer point of view, while implementing an inner perspective of organizations yields mostly individual forms of responsibility. Moreover, the outer perspective on an organization depends on considering it as an organic entity. As such, an organization is seen to act through its members, which are its organs. A crucial point in this picture is that an individual's responsibility is determined by virtue of being a part of an organization, not by any causal aspect of her actions.

In the end, this view enables us to choose between different perspectives regarding collectives and their implications for responsibility. Choosing one perspective-the organic or the mechanical one-should not blind us from evaluating the importance of the path that was not taken. Choosing the right collective perspective is a matter of exercising our faculties for observing ethical nuances. Such a choice represents a finetuning of our moral sensibilities, not a complete renunciation of the path that was not chosen. By exercising these choices we can achieve more balanced attitudes toward individual and collective ways of action in a changing world. We should not take either of these metaphors as tools by which to modify our culture from the basic level.

Collective responsibility is important to my discussion, fleshing out some intuitions about how collective responsibility came to exist in its present form. By studying and questioning notions of collective responsibility, we can better understand our moral attitudes. We are the sort of creatures who tend to blame others, even if we do not think that they are directly connected to whatever harm was done. Our common background 
is clearly communicated through these notions of collective guilt and collective responsibility, as our collective response modes include not only moral condemnation, but also moral appraisal (Forrest, 2006). Our capacity to feel connected to many other humans is also a source of many of our virtues, fueling communities and enabling solidarity.

\section{References}

Anderson, B. (1991). Imagined Communities: Reflections on the Origin and Spread of Nationalism. London: Verso.

Bratman, M. E. (1993). Shared Intention. Ethics, 104, 97-113. http://dx.doi.org/10.1086/293577

Coop, D. (2007). The Collective Moral Autonomy Thesis. Journal of Social Philosophy, 38, 369388.

Fletcher, G. P. (2002). The Storrs Lectures: Liberals and Romantics at War: The Problem of Collective Guilt. 111 YALE L. J, 111, 1499.

Forrest, P. (2006). Collective Guilt; Individual Shame. Midwest Studies in Philosophy: XXX, 145-153. http://dx.doi.org/10.1111/j.1475-4975.2006.00132.x

French, P. (1979). The Corporation as a Moral Person. American Philosophical Quarterly, 16, 207-215.

French, P. (1984). Collective and Corporate Responsibility. New York: Columbia University Press.

Gilbert, M. (2006). Who's to Blame? Collective Moral Responsibility and Its Implications for Group Members. Midwest Studies in Philosophy: XXX, 94-144. http://dx.doi.org/10.1111/j.1475-4975.2006.00130.x

Ginat, J. (1987). Blood Disputes among Bedouin and Rural Arabs in Israel. Pittsburgh: University of Pittsburgh Press \& University of Pittsburgh with Jerusalem Institute for Israeli Studies.

Glouberman, M. (2012). The Raven, the Dove and the Owl of Minerva: The Creation of Humankind in Athens and Jerusalem. Toronto/Buffalo/London: University of Toronto Press.

Isaacs, T. (2006). Collective Moral Responsibility and Collective Intention. Midwest Studies in Philosophy: XXX, 59-73. http://dx.doi.org/10.1111/j.1475-4975.2006.00128.x

Macnamara, C. (2011). Holding Others Responsible. Philosophical Studies, 152, 81-102. http://dx.doi.org/10.1007/s11098-009-9464-9

Mäkelä, P. (2007). Collective Agents and Moral Responsibility. Journal of Social Philosophy, 38, 456-468. http://dx.doi.org/10.1111/j.1467-9833.2007.00391.x

Mayhew, R. (1997). Part and Whole in Aristotle's Political Philosophy. The Journal of Ethics, 1, 325-340. http://dx.doi.org/10.1023/A:1009743012461

Moore, G. M. (1903). Principia Ethica. Cambridge: Cambridge University Press.

Pettit, P. (2007). Responsibility Incorporated. Ethics, 117, 171-201. http://dx.doi.org/10.1086/510695

Radzic, L. (2001). Collective Responsibility and Duties to Respond. Social Theory and Practice, 27, 455-471. http://dx.doi.org/10.5840/soctheorpract20012735

Russell, B. (1905). On Denoting. Mind, New Series, 14, 479-493. http://dx.doi.org/10.1093/mind/XIV.4.479

Sepinwall, A. J. (2010). Responsibility for Group Transgressions. Ph.D. Thesis, Washington DC: Georgetown University. 
Strawson, P. (1993). Freedom and Resentment. In J. M. Fischer, \& M. Ravizza (Eds.), Perspectives on Moral Responsibility (pp. 45-66). Ithaca: Cornell University Press.

Watson, G. (2009). Two Faces of Responsibility. Agency and Answerability (pp. 260-288). New York: Clarendon Press.

Submit or recommend next manuscript to SCIRP and we will provide best service for you:

Accepting pre-submission inquiries through Email, Facebook, LinkedIn, Twitter, etc. A wide selection of journals (inclusive of 9 subjects, more than 200 journals)

Providing 24-hour high-quality service

User-friendly online submission system

Fair and swift peer-review system

Efficient typesetting and proofreading procedure

Display of the result of downloads and visits, as well as the number of cited articles Maximum dissemination of your research work

Submit your manuscript at: http://papersubmission.scirp.org/

Or contact ojpp@scirp.org 